\title{
Primary Localized Cutaneous Nodular Amyloidosis on a Toe: Clinical Presentation, Histopathology, and Dermoscopy Findings
}

\author{
Isadora L.O. Ferreira ${ }^{1}$, Elizabeth L. Fernandes ${ }^{1}$, Jan Lapins ${ }^{2}$, Tatiane Benini ${ }^{1}$, \\ Luciana C. Silva ${ }^{1}$, Marcia A. Lanzoni ${ }^{3}$, Denise Steiner ${ }^{1}$
}

1 Serviço de Dermatologia, Universidade de Mogi das Cruzes, São Paulo, Brazil

2 Department of Dermatology, Karolinska University Hospital, Stockholm, Sweden

3 Serviço de Patologia, Departamento de Medicina, Universidade de Taubaté, São Paulo, Brazil

Key words: dermatology, amyloidosis, nodular amyloidosis, dermoscopy

Citation: Ferreira ILO, Fernandes EL, Lapins J, Benini T, Silva LC, Lanzoni MA, Steiner D. Primary localized cutaneous nodular amyloidosis on a toe: clinical presentation, histopathology, and dermoscopy findings. Dermatol Pract Concept. 2019;9(3):235-236. DOI: https://doi.org/10.5826/dpc.0903a18

Accepted: March 19, 2019; Published: July 31, 2019

Copyright: $\odot 2019$ Ferreira et al. This is an open-access article distributed under the terms of the Creative Commons Attribution License, which permits unrestricted use, distribution, and reproduction in any medium, provided the original author and source are credited.

Funding: None.

Competing interests: The authors have no conflicts of interest to disclose.

Authorship: All authors have contributed significantly to this publication.

Corresponding author: Isadora L.O. Ferreira, MD, Rua Dom Antonio Candido de Alvarenga 170, Mogi das Cruzes, São Paulo, Brazil, 08780-070. Email: isadora_lopes@hotmail.com

\section{Introduction}

Amyloidosis represents a group of diseases characterized by extracellular deposition of amyloid and is traditionally classified as systemic or localized. Primary localized cutaneous nodular amyloidosis (PLCNA) is the rarest form of cutaneous amyloidosis, usually occurring equally among genders. It manifests as single or multiple nodules or infiltrated plaques, usually localized on the face, particularly the nose, genitals, trunk, and limbs. Progression to systemic involvement is quite uncommon, occurring in approximately $7 \%$ of cases [1].

\section{Case Presentation}

A 71-year-old-man from São Paulo, Brazil, with no comorbidities, presented with a 5 -year history of an asymptomatic single, soft, large, elongated pink nodule in the toe web along the fourth left toe (Figure 1, A and B). Polarized contact dermoscopy showed white shiny streaks on orange-pink background (Figure 1C). A local ultrasound examination revealed a hypoechoic tumor measuring $2.3 \times 1.3 \times 1.2 \mathrm{~cm}$ that extended to subcutaneous tissues. Differential diagnostic possibilities as acral manifestations of soft tissue tumors including superficial acral fibromyxoma, inclusion body fibromatosis, and acral fibrokeratoma were considered. Histopathology from a punch biopsy showed an epidermis with focal mild spongiosis, parakeratosis, and lymphocyte exocytosis together with a proliferation of desmoplastic spindle cells with a nonspecific lymphoplasmocytic inflammatory process.

Immunohistochemical examination was inconclusive. Histopathology from complete excision showed that throughout the dermis, there were nodular deposits of hyaline and eosinophilic material, with spindle-shaped cells (Figure 1D). Hyaline-like, eosinophilic material was also seen in the walls of small vessels and subcutaneous 
tissue. Congo red staining showed the presence of a brick-red deposit in the dermis (Figure 1E), which under polarizing microscopy showed apple-green birefringence. The diagnosis of PLCNA was established based on clinical findings and histopathology in the absence of systemic manifestations of amyloidosis. Beside the lesion on the foot, the patient was asymptomatic. Complete blood cell count, B-glucose, electrophoresis, ANA test, urine test, and Bence Jones protein test results were normal. Abdominal ultrasound and chest X-ray showed nothing remarkable. No systemic manifestations of amyloidosis were identified. The patient is undergoing 6-month follow-up intervals with clinical and laboratory examinations. After 1 year no recurrence was detected.

\section{Conclusions}

We describe a rare presentation of primary cutaneous amyloidosis located on an uncommon body site. Polarized dermoscopy examination could have contributed to the clinical suspicion of the correct diagnosis in this case. Skin lesions with an altered composition or orientation of collagen will often reveal, under polarized dermoscopy, shiny white streaks [2]. In polarized dermoscopy of lichen amyloidosis, the deposition of amyloid substance with birefringent properties in the dermis is reported to be visualized as shiny white streaks [2]. A case report of dermoscopy of PLCNA described an orange hue, otherwise seen in dermal granulomatous skin disorders, as a clue for diagnosis [3]. The dermoscopic pattern of polarization-specific white structures in a background of orange-pink color, present in our case, could be an additional feature that can contribute to the PLCNA diagnosis.
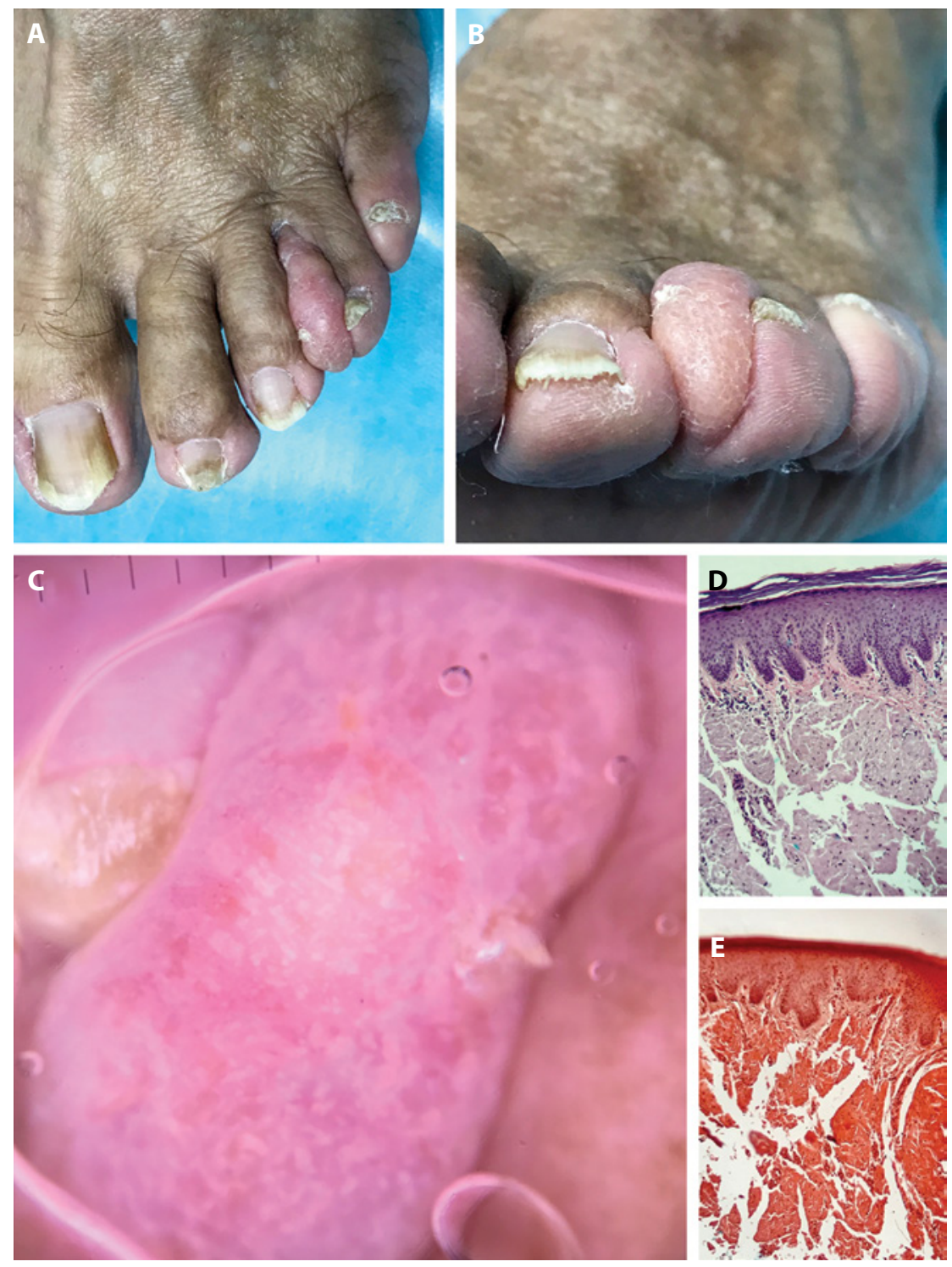

Figure 1. (A, B) Clinical presentation of a single, soft, pink nodule on the fourth left toe. (C) Polarized contact dermoscopy of the lesion showing birefringent properties present as shiny white structures on orange-pink background. (D) Histopathological examination of the lesion shows hyaline eosinophilic nodular deposits, with spindle-shaped cells throughout the dermis. (E) Histopathological characteristics of the lesion, using Congo red staining evidencing presence of a brick-red deposit in the dermis. [Copyright: (C2019 Ferreira et al.]

Dermoscopic findings of PLCNA have not been extensively described in the literature, and we suggest that polarized dermoscopy can be a complementary and useful aid for noninvasive diagnosis.

\section{References}

1. Woollons A, Black MM. Nodular localized primary cutaneous amyloidosis: a long-term follow-up study. Br J Dermatol. 2001;145(1):105-109.

2. Arnold SJ, Bowling JC. "Shiny white streaks" in lichen amyloidosis: a clue to diagnosis. Australas J Dermatol. 2012;53(4):272-273.

3. Rongioletti F, Atzori L, Ferreli C, et al. A unique dermoscopy pattern of primary cutaneous nodular amyloidosis mimicking a granulomatous disease. J Am Acad Dermatol. 2016;74(1):e9-e10. 